\title{
Lack of Blood Pressure Control in Italy: Room for Improvement?
}

\author{
M. Lorenza Muiesan
}

Received: 10 November 2014/ Accepted: 21 November 2014/Published online: 3 December 2014

(C) Springer International Publishing Switzerland 2014

High blood pressure (BP) represents one of the most important risk factors for cardiovascular, cerebrovascular and renal diseases. It has been observed that about $60 \%$ of strokes and $50 \%$ of coronary events may be attributed to the increase in BP values above "optimal levels". In addition about $2 / 3$ of these events occur in relatively young subjects (45-69 years) and in about $50 \%$ of cases patients show only a slight increase in systolic BP values (between 130 and $150 \mathrm{mmHg}$ ) [1]. Epidemiologists have calculated the future prevalence of arterial hypertension prevalence in the next 10 years; the projection suggests an increase up to $60 \%$ prevalence worldwide in 2025 [1]. This increase is mainly the consequence of aging and of unfavourable lifestyle changes in developing countries, characterized by a growing incidence of obesity, smoking habits, sedentary life and salt consumption. In the United States arterial hypertension accounts for 40 million office visits per year and for more than $\$ 93$ billion in total costs [2].

Despite a solid and undisputable evidence of the efficacy of antihypertensive treatment in cardiovascular prevention, the awareness, treatment and control of elevated BP values are still low in most industrialized countries, including Italy [3-8]. Poor BP control rates have been reported also by large observational studies and clinical surveys, performed in different clinical settings and in different countries. The lack of BP control translates in a significant increase in the incidence of stroke, coronary artery disease, heart failure and chronic kidney disease.

Recent data collected in several European countries and in Italy have shown that among treated patients only about

M. L. Muiesan ( $₫)$

Dipartimento di Scienze Cliniche e Sperimentali,

Università di Brescia, Brescia, Italy

e-mail: marialorenza.muiesan@unibs.it
$30 \%$ reach an adequate BP control [3-8]. In Italy it has been documented that in years between 2005 and 2011 only $60 \%$ of subjects with high BP are treated and among them the reduction of BP below $140 / 90 \mathrm{mHg}$ is observed in $37 \%$. Data have also shown that efforts towards a more rigorous control of $\mathrm{BP}$ should be even more stringent because of the greater event-saving effect of BP control when the cardiovascular risk is high.

As an obvious consequence of these evidences a main goal of our national health service should be the improvement of prevention strategies aimed to identify, treat and control all hypertensive patients, and with a longterm economic advantage for the National Health Service.

Several factors have been associated with poor control, some of which involve the characteristic of the patients themselves, such as socioeconomic factors, or unsuitable life-styles. Other factors are related to hypertension or to associated comorbidity, or directly associated with antihypertensive therapy, mainly involving adherence problems, therapeutic inertia and therapeutic strategies unsuited to difficult-to-control hypertensive patients.

Since 2012 the Italian Society of Hypertension (SIIA), in collaboration with the Italian Society of General Practitioner (SIMG) has promoted several actions addressing the issue of BP control, with the ambitious goal of controlling $70 \%$ of the Italian hypertensive population $[9,10]$. Among these initiatives the SIIA has rigorously updated and published on Society's website the number of Hypertension Excellence Centers and of Outpatients Clinics for Hypertension in the country, addressing also the minimum requirements [10], and has produced practical recommendations for clinical management of hypertensive patients [11].

Several other actions have been proposed to reach a more effective control BP in hypertensive patients in Italy, 
such as early diagnosis, lifestyle implementation, choice of treatment, including drug combinations, use of home BP measurement to improve patients' compliance.

A group of Italian General Practitioners (GPs) [6] have confirmed that a successful improvement in "real practice" may be obtained by a simple organized approach in primary care, with an increase of BP control rate to $64 \%$ [12].

In this new study Filippi et al. [13] go deeper into the problem, aiming to evaluate the obstacles that may justify a further improvement in BP control. All GPs examined their records and identified the prevalence of patients without BP control in the last year. A prespecified questionnaire was administered about their methods, investigating the reasons for the lack of $\mathrm{BP}$ control or BP recordings. The results of the study show that among patients without an adequate BP control, one third have BP is higher than cutoff values suggested by guidelines. In these uncontrolled patients with available measurements of BP, several reasons, related both to patient's and/or doctor's behavior have been identified and are mainly represented by patient choice (29\%), wait and see strategy (26\%), clinically inappropriate increase in therapy $(20 \%)$; other less frequent reasons are secondary or resistant hypertension or other physicians caring for the patient.

However in the largest remaining proportion (66\%) of "uncontrolled" hypertensive patients, BP recordings in the last year are missing. The lack of available BP recordings is mainly due to difficulties in direct contact between the patient and the doctor or in a smaller proportion to the use of home BP self monitoring, without a copy of home measurements.

The results of this survey provide a further insight in the different reasons for inadequate BP control and may represent an useful indication for corrective approaches. In particular the use of new telemedicine technologies could allow the share of health information (and not only BP) between the patient and the doctor(s) overriding the problem of attending the doctor's office, in patients that use home BP measurements or go to the pharmacist [14-16]. To reach this goal, however, the collaboration between GPs, specialists and other professional is mandatory.

Most importantly, priority should be given to interventions that bring to the doctor hypertensive patients that refuse to be seen, even after recalling messages. In the paper of Filippi et al., more details on sociodemographic characteristics (age, sex, smoking habits, weight, marriage status, occupational situation etc.) of these subjects would have been of interest, in order to propose the best approaches to improve education on $\mathrm{CV}$ risk and prevention as well as motivation to life style measures and/or pharmacological therapy. Patient-doctor communication is fundamental to this regard, although the efficacy of programs to improve communication skills needs to be proven in large scale studies.

The accurate analysis by Filippi et al. [13] is performed in a small group of selected, motivated and dedicated doctors and cannot be generalized to all the Italian GPs, but represents a great effort and confirms the eagerness, expressed in the past, to influence public health changes, because of the severe impact of uncontrolled BP levels on the increased risk of cardiovascular diseases in terms of morbidity, mortality and socio-economic burden. We strongly hope that in the future a larger number of GPs will benefit and will be able to take advantage from the remarkable amount of work that Filippi and his colleagues have produced in the field of cardiovascular disease prevention.

\section{References}

1. Hypertension: an urgent need for global control and prevention. Lancet. 2014;383(9932): 1861.

2. Centers for Disease Control and Prevention (CDC). Vital signs: prevalence, treatment, and control of hypertension-United States, 1999-2002 and 2005-2008. MMWR Morb Mortal Wkly Rep. 2011;60(4):103-8.

3. Guallar E, et al. Excess risk attributable to traditional cardiovascular risk factors in clinical practice settings across Europethe EURIKA Study. BMC Pub Health. 2011;11:704.

4. Grassi G, Cifkova R, Laurent S, Narkiewicz K, Redon J, Farsang $\mathrm{C}$, et al. Blood pressure control and cardiovascular risk profile in hypertensive patients from central and eastern European countries: results of the BPCARE study. Eur Heart J. 2011;32:218-25.

5. Volpe M, Tocci G, Trimarco B, et al. Blood pressure control in Italy: results of recent surveys on hypertension. J Hypertens. 2007;25:1491-8.

6. Filippi A, Paolini I, Innocenti F, Mazzaglia G, Battaggia A, Brignoli $\mathrm{O}$. Blood pressure control and drug therapy in patients with diagnosed hypertension: a survey in Italian general practice. J Hum Hypertens. 2009;23:758-63.

7. Tocci G, Agabiti-Rosei E, Ambrosioni E, et al. Blood pressure control in Italy: analysis of clinical data from 2005-2011 surveys on hypertension. J Hypertens. 2012;30:1065-74.

8. Brambilla G, Bombelli M, Seravalle G, et al. Prevalence and clinical characteristics of patients with true resistant hypertension in central and Eastern Europe: data from the BP-CARE study. J Hypertens. 2013;31:2018-24.

9. Muiesan ML, Salvetti M, Rizzoni D, Paini A, Agabiti-Rosei C, Aggiusti C. Agabiti Rosei E. Resistant hypertension and target organ damage. Hypertens Res. 2013;36:485-91.

10. Tocci G, De Luca N, Sarzani R, Ambrosioni E, Borghi C, Cottone S, Cuspidi C, Fallo F, Ferri C, Morganti A, Muiesan ML, Sechi L, Virdis A, Mancia G, Volpe M. National survey on excellence centers and reference centers for hypertension diagnosis and treatment: geographical distribution, medical facilities and diagnostic opportunities. High Blood Press Cardiovasc Prev. 2013.

11. Volpe M, Rosei EA, Ambrosioni E, Cottone S, Cuspidi C, Borghi C, De Luca N, Fallo F, Ferri C, Morganti A, Muiesan ML, Sarzani R, Sechi L, Virdis A, Tocci G, Trimarco B, Filippi A, Mancia G. 2012 Consensus document of the Italian Society of 
Hypertension (SIIA): strategies to improve blood pressure control in Italy: from global cardiovascular risk stratification to combination therapy. High Blood Press Cardiovasc Prev. 2013;20(1): $45-52$.

12. Filippi A, Sangiorgi D, Buda S, Degli Esposti L, Nati G, Paolini I, Di Guardo A. How many hypertensive patients can be controlled in "real life": an improvement strategy in primary care. BMC Fam Pract. 2013;14:192.

13. Filippi A. Why is my hypertensive patient still not controlled. HBPCVP. 2014 (in press).

14. Parati G, Omboni S, Compare A, Grossi E, Callus E, Venco A, Destro M, Villa G, Palatini P, Rosei EA, Scalvini S, Taddei S, Manfellotto D, Favale S, De Matteis C, Guglielmi M, TELEBPMET Study Group, Lonati L, Della Rosa F, Tosazzi E, Grandi AM, Maresca AM, Mongiardi C, Mare M, Ricci AR, Cagnoni F, Georgatos J, Besostri V, Ferrari V, Omodeo O, Dorigatti F, Bonso E, Guarnieri C, Muiesan L, Paini A, Stassaldi D,
Cinelli A, Bernocchi P, Rocchi S, Magagna A, Ghiadoni L, Del Frate I, Boresi F, Guidi A, Re MA, Pellicciotti L, Florio A, Morani G, Di Lillo S, Ambrosio A, Casciello A, Quaglia M, Forleo C, Ardito MA, Gerunda S, Panunzio M. Blood pressure control and treatment adherence in hypertensive patients with metabolic syndrome: protocol of a randomized controlled study based on home blood pressure telemonitoring vs. conventional management and assessment of psychological determinants of adherence (TELEBPMET Study). Trials. 2013;23(14):22.

15. Omboni S, Gazzola T, Carabelli G, Parati G. Clinical usefulness and cost effectiveness of home blood pressure telemonitoring: meta-analysis of randomized controlled studies. J Hypertens. 2013;31(3):455-67.

16. Bernocchi P, Baratti D, Zanelli E, Rocchi S, Salvetti M, Paini A, Scalvini S. Six-month programme on lifestyle changes in primary cardiovascular prevention: a telemedicine pilot study. Eur J Cardiovasc Prev Rehabil. 2011;18(3):481-7. 